\title{
Iron deficiency correction in heart failure patients with preserved ejection fraction: a case series study
}

Eugenio Roberto Cosentino, Arrigo Francesco Giuseppe Cicero, Crescenzio Bentivenga, Marianna Burchi, Claudio Borghi

IRCCS Policlinico S. Orsola-Malpighi, Hypertension and Cardiovascular Risk Research Unit, DIMEC, University of Bologna, Bologna, Italy

Submitted: 10 February 2021, Accepted: 23 April 2021

Online publication: 5 May 2021

Arch Med Sci 2021; 17 (4): 1137-1139

DOI: https://doi.org/10.5114/aoms/136068

Copyright (c) 2021 Termedia \& Banach

According to the European Society of Cardiology (ESC) guidelines, iron deficiency (ID) in patients with heart failure (HF) is defined as ferritin $<100 \mu \mathrm{g} / \mathrm{l}$ (absolute ID) or ferritin 100-300 $\mathrm{\mu g} / \mathrm{l}$ combined with transferrin saturation (TSAT) $<20 \%$ (functional ID) [1]. ID is as highly prevalent is the chronic HF population as 30-79\% [2]. Nevertheless, in patients with $\mathrm{HF}$ with preserved ejection fraction (HFpEF) ID is less studied: according to the meta-analysis by Beale et al. it is estimated as $59 \%$ in these subjects [3]. The ESC guidelines recommend (IC) that all patients with symptomatic chronic HF undergo screening for ID [1]. Since ID and HF share symptoms such as fatigue and dyspnoea, in HF patients ID is often underdiagnosed and not corrected. Indeed, only a dedicated blood sample establishes the diagnosis. Ferric carboxymaltose (FCM) is the most studied compound in HF and it is the only iron supplementation recommended by the ESC guidelines [1]. To the best of our knowledge no data have been published so far on the use of FCM in patients with HFpEF.

The aim of the study was to evaluate the effect and safety of FCM in ID correction in chronic HFpEF patients as regards symptoms (NYHA class), Nt-proBNP and iron status 12 months after FCM infusion. This is a case series study: reports of several patients with a given condition, usually covering the course of the condition and the response to treatment. There is no comparison (control) group of patients [4].

A prospective series of consecutive chronic HFpEF patients with ID was enrolled from January 2018 to October 2019. They were screened and followed up at our HF clinic.

The diagnosis of HFpEF was made according to ESC HF 2016 Guidelines: the presence of symptoms and/or signs of HF, LVEF $\geq 50 \%$, levels of NT-proBNP > $125 \mathrm{pg} / \mathrm{ml}$ and left ventricular mass index (LVMI) $\geq 115$ $\mathrm{g} / \mathrm{m}^{2}$ for males and $\geq 95 \mathrm{~g} / \mathrm{m}^{2}$ for females [1]. ID was defined as ferritin $<100 \mu \mathrm{g} / \mathrm{l}$ or ferritin 100-300 $\mu \mathrm{g} / \mathrm{l}$ and transferrin saturation (TSAT) $<20 \%$. Inclusion criteria were: at least 18 years old, chronic stable HFpEF NYHA class I, II or III and ID. Exclusion criteria were: congenital heart disease or NYHA class IV. Blood samples were collected after $12 \mathrm{~h}$ of fasting and processed with standardized methods. Every patient underwent transthoracic echocardiography in left lateral decubitus. Every recording was done at end expiration, with ECG tracking. According to the American Society of Echocardiography, patients were evaluated in parasternal long-axis and short-axis views, as well as in apical views, to calculate EF according to the modified Simpson's biplane method [5]. The FCM dose was calculated on the basis of iron need, from

\author{
Corresponding author: \\ Prof. Arrigo F.G. Cicero MD, PhD \\ IRCCS Policlinico \\ S. Orsola-Malpighi \\ Hypertension and \\ Cardiovascular Risk \\ Research Unit \\ DIMEC \\ University of Bologna \\ Bologna, Italy \\ E-mail: arrigo.cicero@unibo.it
}


$500 \mathrm{mg}$ once to a maximum of $1000 \mathrm{mg} /$ week of FCM to reach the required dose according to SmPC. At 7 days after the first infusion the reticulocyte count was checked, as were haemoglobin, eGFR and iron status after 14 days. If necessary, the iron need was then recalculated. Every patient agreed to the use of personal data and gave his/her written informed consent to participate. The study was conducted according to the Declaration of Helsinki and was approved by the local ethics committee. The study was conducted according to the Declaration of Helsinki. The study was approved by the local ethics committee "AVEC-Large area ethical committee-Emilia Romagna, Bologna, Italy".

Statistical analysis was performed using IBM SPSS Statistics 19.0 for Windows (SPSS, Inc., Chicago, IL). The level of two-tailed statistical significance was set at $p<0.05$. Continuous variables were expressed as mean and standard deviation or median and interquartile range, and the difference between means was tested by Student's $t$-test for paired or unpaired samples.

Of the 82 enrolled patients, 41 (50\%) were male with a range of age of 49-95 years (males $77 \pm 10$, females $79 \pm 7$ ). Basal body mass index was $28 \pm 6 \mathrm{~kg} / \mathrm{m}^{2}$. Mean disease duration was 3 years (range: $1-16)$. The distribution according to NYHA class was 14\% NYHA I, 55\% NYHA II and 31\% NYHA III. NT-proBNP was 1200 (543-1207) pg/ml. Left ventricular mass index (LVMI) was $133 \pm 18 \mathrm{~g} / \mathrm{m}^{2}$ for males and $110 \pm 12 \mathrm{~g} / \mathrm{m}^{2}$ for females. As regards HF aetiology, $76 \%$ were hypertensive, $18 \%$ both hypertensive and ischemic, $6 \%$ valvular. The cohort was highly complex considering comorbidities: $18 \%$ with a history of myocardial infarction, $8 \%$ underwent revascularization, 33\% was diabetic, $7 \%$ with a pre-existent cerebrovascular event, $70 \%$ with dyslipidaemia, 38\% with chronic obstructive

Table I. Clinical characteristics at baseline and at follow-up

\begin{tabular}{|lcc|}
\hline Variable & Basal & $\begin{array}{l}\text { 12-month } \\
\text { follow-up }\end{array}$ \\
\hline $\begin{array}{l}\text { Systolic blood } \\
\text { pressure [mm Hg] }\end{array}$ & $130 \pm 13$ & $131 \pm 15$ \\
\hline $\begin{array}{l}\text { Diastolic blood } \\
\text { pressure [mm Hg] }\end{array}$ & $78 \pm 8$ & $78 \pm 7$ \\
\hline $\begin{array}{l}\text { Left ventricular } \\
\text { ejection fraction (\%) }\end{array}$ & $60 \pm 7$ & $64 \pm 4$ \\
\hline Nt-proBNP [pg/ml] & $200(543-1207)$ & $300(200-600)^{*}$ \\
\hline $\begin{array}{l}\text { eGFR } \\
\text { [ml/min/1.73 m }{ }^{*} \text { ] }\end{array}$ & $49 \pm 19$ & $50 \pm 20$ \\
\hline Haemoglobin [g/dl] & $12 \pm 1.7$ & $12.6 \pm 1.4^{*}$ \\
\hline Iron [ $\mu$ g/dl] & $46 \pm 19$ & $80 \pm 25^{*}$ \\
\hline Ferritin [ng/dl] & $43(22-99)$ & $249(121-405) *$ \\
\hline TSAT (\%) & $13 \pm 7$ & $26 \pm 7^{*}$ \\
\hline${ }^{*}<0.05$ than baseline. & & \\
\hline
\end{tabular}

pulmonary disease, $56 \%$ with mild-to-moderate chronic kidney disease, 54\% with permanent atrial fibrillation, $22 \%$ with dysthyroidism. The patients were at optimized medical therapy: $51 \%$ were taking ACE inhibitors, $41 \%$ angiotensin II receptor blockers, $41 \%$ mineralocorticoid receptor antagonists, $82 \% \beta$-blockers, $41 \%$ calcium channel blockers, $94 \%$ diuretics, 55\% statins, 56\% antiplatelet agents, $34 \%$ warfarin and $14 \%$ direct oral anticoagulants. The therapy has been unchanged since at least 4 weeks and remained the same during the follow-up period. Adherence to therapy was confirmed by the patients.

The mean dose of FCM administered was $14081 \pm 314 \mathrm{mg}$. A follow-up visit was performed 12 month \pm 3 weeks after the screening visit.

At the follow-up visit NYHA functional class significantly improved from NYHA I 14\%, NYHA II $55 \%$ and NYHA III 31\% to 44\%, 49\%, 7\%, respectively. In our patients FCM improved iron status, haemoglobin level as well as Nt-proBNP (Table I). At the follow-up visit $27 \%$ of patients had again ID (17\% absolute and $10 \%$ functional) and required further administration. If necessary, another FCM infusion was performed after collecting the data for this analysis.

FCM is able to improve exercise capacity, quality of life and reduction of $\mathrm{HF}$ hospitalizations in patients with $\mathrm{HF}$ with reduced $\mathrm{EF}$ (HFrEF), but no data are yet available as regards its effect on HFpEF patients [6-8]. The main findings of this study are that correcting ID with FCM in our cohort of patients with chronic stable HFpEF seems to improve NYHA class, Nt-proBNP and iron status. Notably, most (71\%) patients needed only a single replenishment treatment with FCM within 12 months, confirming the applicability of this drug to correct ID also in a cohort of HFpEF and comorbid patients. Notably, despite the presence of several comorbidities in our complex and poly-treated cohort, no patients withdrew from the treatment. In our cohort we registered 2 deaths, neither related to FCM use. During the follow-up there were 4 all-cause hospitalizations, none related to the use of FCM. One patient complained of nausea and 2 patients complained of ache at the infusion site. To the best of our knowledge, these are the first data about ID correction in HFpEF. Obviously, the study design did not allow us to get conclusive findings about the treatment of HFpEF patients. Adequately powered randomised controlled trials, such as the ongoing FAIR-HFpEF (NCT03074591), will be needed to answer this question. Our study suffers from some limitations. First, the lack of a control group does not let us exclude the presence of confounding factors and generalizability is not possible outside the treated group. Moreover, our sample size is small. In con- 
clusion, at 12 months of follow-up in our patients with chronic stable HFpEF, FCM administration seems to improve NYHA class, Nt-proBNP and iron status.

\section{Conflict of interest}

The authors declare no conflict of interest.

\section{References}

1. Ponikowski P, Voors AA, Anker SD, et al.; ESC Scientific Document Group. 2016 ESC Guidelines for the diagnosis and treatment of acute and chronic heart failure: The Task Force for the diagnosis and treatment of acute and chronic heart failure of the European Society of Cardiology (ESC) Developed with the special contribution of the Heart Failure Association (HFA) of the ESC. Eur Heart J 2016; 37: 2129-200.

2. Jankowska EA, Rozentryt P, Witkowska A, et al. Iron deficiency: an ominous sign in patients with systolic chronic heart failure. Eur Heart J 2010; 31: 1872-80.

3. Beale AL, Warren JL, Roberts N, Meyer P, Townsend NP, Kaye D. Iron deficiency in heart failure with preserved ejection fraction: a systematic review and meta-analysis. Open Heart 2019; 6: e001012.

4. https://www.nice.org.uk/glossary?letter=c

5. Lang RM, Badano LP, Mor-Avi V, et al. Recommendations for cardiac chamber quantification by echocardiography in adults: an update from the American Society of Echocardiography and the European Association of Cardiovascular Imaging. J Am Soc Echocardiogr 2015; 28: 1-39.e14.

6. Hoes MF, Grote Beverborg N, Kijlstra JD, et al. Iron deficiency impairs contractility of human cardiomyocytes through decreased mitochondrial function. Eur J Heart Fail 2018; 20: 910-9.

7. Chopra VK, Anker SD. Anaemia, iron deficiency and heart failure in 2020: facts and numbers. ESC Heart Fail 2020; 7: 2007-11.

8. Anker SD, Comin Colet J, Filippatos G, et al.; FAIR-HF Trial Investigators. Ferric carboxymaltose in patients with heart failure and iron deficiency. N Engl I Med 2009; 361: 2436-48. 